OPEN Molecular phylogeny of Orthetrum

SUBJECT AREAS:

ENTOMOLOGY

TAXONOMY

SYSTEMATICS

PHYLOGENETICS

Received

28 November 2013

Accepted

13 June 2014

Published

3 July 2014

Correspondence and requests for materials should be addressed to P.-E.L. (phaikeem@um. edu.my)

\section{dragonflies reveals cryptic species of Orthetrum pruinosum}

\author{
Hoi Sen Yong ${ }^{1}$, Phaik-Eem Lim ${ }^{1,2}$, Ji Tan ${ }^{1,2}$, Yong Foo $\mathrm{Ng}^{3}$, Praphathip Eamsobhana ${ }^{4}$ \& I. Wayan Suana ${ }^{5}$
}

'Institute of Biological Sciences, University of Malaya, 50603 Kuala Lumpur, Malaysia, ${ }^{2}$ Institute of Ocean and Earth Sciences, University of Malaya, 50603 Kuala Lumpur, Malaysia, ${ }^{3}$ Centre for Insect Systematics, School of Environmental and Natural Resource Sciences, Faculty of Science and Technology, Universiti Kebangsaan Malaysia, 43000 Bangi, Selangor D.E., Malaysia, ${ }^{4}$ Department of Parasitology, Faculty of Medicine Siriraj Hospital, Mahidol University, Bangkok 10700, Thailand, ${ }^{5}$ Faculty of Science and Mathematics, Mataram University, Mataram, Indonesia.

Dragonflies of the genus Orthetrum are members of the suborder Anisoptera, family Libellulidae. There are species pairs whose members are not easily separated from each other by morphological characters. In the present study, the DNA nucleotide sequences of mitochondrial and nuclear genes were employed to elucidate the phylogeny and systematics of Orthetrum dragonflies. Phylogenetic analyses could not resolve the various subfamilies of the family Libellulidae unequivocally. The nuclear 28S rRNA gene is highly conserved and could not resolve congeneric species of Orthetrum. Individual mitochondrial genes (COI, COII, and $16 \mathrm{~S}$ rRNA) and combination of these genes as well as the nuclear ITS1\&2 genes clearly differentiate morphologically similar species, such as the reddish species pairs $O$. chrysis and $O$. testaceum, and the bluish-coloured species $O$. glaucum and $O$. luzonicum. This study also reveals distinct genetic lineages between $O$. pruinosum schneideri (occurring in Malaysia) and $O$. pruinosum neglectum (occurring north of Peninsular Malaysia from India to Japan), indicating these taxa are cryptic species.

D

ragonflies of the genus Orthetrum Newman, 1833 are members of the suborder Anisoptera, family Libellulidae. The genus contains some 61 species spread across the Old World ${ }^{1}$. Among these Orthetrum dragonflies, there are species pairs whose members are not easily separated from each other by morphological characters, e.g. the reddish-coloured species $O$. chrysis and O. testaceum, and the bluishcoloured species O. glaucum and O. luzonicum.

The Crimson-tailed Marsh Hawk Orthetrum pruinosum (Burmeister, 1839) is a widespread species occurring from west India to Japan and south to Malaysia and the Sunda Islands. The subspecies in Malaysia is $O . p$. schneideri Förster, 1903 and that north of Peninsular Malaysia (India to Japan) is O. p. neglectum (Rambur, 1842).

The DNA nucleotide sequences of mitochondrial and nuclear genes have been employed to elucidate the phylogeny and systematics of Orthetrum dragonflies ${ }^{2,3}$. To-date the most comprehensive phylogenetic study of Orthetrum dragonflies involves all the nine Japanese species ${ }^{2}$. In the present study, the DNA nucleotide sequences of mitochondrial and nuclear genes were employed to elucidate the phylogeny and systematics of Orthetrum dragonflies. This study, covering a more extensive taxon sampling, provides a new insight to the evolutionary relationships of Orthetrum dragonflies. The molecular phylogeny based on ITS1\&2, COI, COII and $16 \mathrm{~S}$ nucleotide sequences, reveals the occurrence of cryptic species in O. pruinosum.

\title{
Results
}

Aligned sequences and genetic divergence. The total length for each aligned sequences for various molecular markers and their parsimony information are sumarised in Supplementary Table 1. The uncorrected ' $\mathrm{p}$ '-distance between Orthetrum species based on $16 \mathrm{~S}$ rDNA, COI, combined COI $+16 \mathrm{~S}$ rDNA, combined COI + COII $+16 \mathrm{~S}$ rDNA, ITS1\&2, and combined COI + COII + 16S rDNA + 28S rDNA + ITS1\&2 nucleotide sequences are summarized in supplementary Tables $2-6$ respectively. The interspecific ' $\mathrm{p}$ ' distance was many folds larger than intraspecific ' $\mathrm{p}$ ' distance. For COI, the intraspecific p-distance ranged from $0.00-3.99 \%$ (highest in O. melania), while interspecific p-distance ranged from 3.33\% (O. melania and O. triangulare) to $17.29 \%$ (O. chrysis and $O$. sabina) (Supplementary Table 2). For $16 \mathrm{~S}$ rDNA, the intraspecific p-distance ranged from $0.00-2.10 \%$ (highest in 
O. glaucum); the interspecific p-distance ranged from $0.60 \%(O$. melania and O. triangulare) to $9.92 \%$ (O. abbotti and O. poecilops) (Supplementary Table 2).

The intraspecific p-distance for ITS1\&2 sequences ranged from $0.00-5.05 \%$ (highest in O. luzonicum); the interspecific p-distance ranged from $1.14 \%$ (O. pruinosum neglectum and O. testaceum) to $21.12 \%$ (O. sabina and O. chrysostigma) (Supplementary Table 3).

The intraspecific p-distance for the combined COI $+16 \mathrm{~S}$ rDNA sequences ranged from $0.00-1.78 \%$ (highest in O. sabina); the interspecific p-distance ranged from $1.15 \%$ (O. pruinosum neglectum and O. testaceum) to $12.23 \%$ (O. chrysis and O. Sabina; O. japonicum and O. Sabina) (Supplementary Table 4). For the combined mitochondrial markers (COI + COII $+16 \mathrm{~S}$ rDNA) the intraspecific p-distance ranged from $0.00-1.94 \%$ (highest in O. pruinosum schneideri); the interspecific p-distance ranged from $7.32 \%$ (O. chrysis and $O$. pruinosum schneideri) to $12.58 \%$ (O. chrysis and O. sabina) (Supplementary Table 5).

For the combined five markers $(\mathrm{COI}+\mathrm{COII}+16 \mathrm{~S}$ rDNA $+28 \mathrm{~S}$ rDNA + ITS1\&2) the intraspecific p-distance ranged from $0.00-$ $1.55 \%$ (highest in O. pruinosum schneideri); the interspecific p-distance ranged from $4.20 \%$ (O. chrysis and O. sabina) to $9.51 \%$ (O. chrysis and O. sabina) (Supplementary Table 6).

Phylogenetic relationships based on 28S rDNA nucleotide sequences. There were no distinct nucleotide sequence divergence among the congeners of Orthetrum (supplementary Fig. 1). The various subfamilies of the family Libellulidae were not resolved unequivocally.

Phylogenetic relationships based on 16S rDNA nucleotide sequences. Orthetrum pruinosum schneideri clustered with $O$. chrysis and both were distinctly separated from $O$. testaceum and O. pruinosum neglectum (Fig. 1). O. sabina from Peninsular Malaysia was not grouped together with $O$. sabina of India, Japan and Fiji. Additionally, O. luzonicum from Peninsular Malaysia was distinct from O. luzonicum of China and Japan.

Phylogenetic relationships based on COI nucleotide sequences. Orthetrum pruinosum schneideri clustered with O. chrysis and both were distinctly separated from $O$. testaceum and O. pruinosum neglectum (Fig. 2). The peninsular Malaysian taxon of O. luzonicum clustered with those of China and Japan. Likewise, O. sabina from Peninsular Malaysia clustered with O. sabina of India, Japan and Fiji.

Phylogenetic relationships based on COII nucleotide sequences. There were two major clusters of Orthetrum species (supplementary Fig. 2): (I) [O. pruinosum schneideri, O. chrysis], O. testaceum, O. melania, O. luzonicum, O. glaucum, O. albistylum with weak support posterior probability $(\mathrm{PP}=0.51)$ values and no support from maximum likelihood (ML); and (II) O. sabina.

Phylogenetic relationships based on ITS1 and ITS2 nucleotide sequences. The ITS nuDNA nucleotide sequences clearly separated O. pruinosum schneideri and O. pruinosum neglectum (Fig. 3) indicating distinct genetic lineages. O. pruinosum schneideri nested with $O$. chrysis while O. pruinosum neglectum nested with $O$. testaceum. The component taxa of Orthetrum were grouped in two distinct clades separated by a clade of other Libellulid genera. $O$. sabina was not nested with other Orthetrum taxa. The genus Orthetrum and the Libellulid subfamilies were not monophyletic.

Phylogenetic relationships based on combined nucleotide sequences. The combined COI and COII sequences yielded three major clusters (Fig. 4): (I) [O. pruinosum schneideri, O. chrysis], O. testaceum, O. triangulare, O. luzonicum with PP supoprt of 0.92 and no support from ML; (II) O. glaucum; and (III) O. sabina.
Similar topology resulted from the combined COI + COII $+16 \mathrm{~S}$ rDNA nucleotide sequences (supplementary Fig. 3). The combined 5 markers (supplementary Fig. 4) showed three clades: (I) O. chrysis, $O$. pruinosum schneideri, O. testaceum; (II) O. glaucum, O. sabina; and (III) O. luzonicum.

The combined COI $+16 \mathrm{~S}$ rDNA sequences of Orthetrum taxa formed five major clusters (Fig 5): (I) [O. pruinosum schneideri, O. chrysis], O. testaceum, O. pruinosum neglectum, O. melania; (II) [O. internum, O. japonicum], O. poecilops, O. albistylum; (III) O. luzonicum; (IV) O. glaucum; and (V) O. sabina. The first four clusters (IIV) had full PP and high ML support except cluster V with moderate support of $\mathrm{PP}=0.79$ and $\mathrm{ML}=79 \%$.

\section{Discussion}

The phylogeny of the dragonflies (suborder Anisoptera) has been extensively studied ${ }^{4-10}$. Nine genera of Libellulidae have been reported to be monophyletic ${ }^{11}$. In the present study with more extensive taxon sampling, the various subfamilies of the family Libellulidae as well as the component taxa of the genus Orthetrum were not resolved unequivocally as monophyletic by the $28 \mathrm{~S} \mathrm{rDNA}$ (supplementary Fig. 1), 16S rDNA (Fig. 1), COI (Fig. 2), and ITS1\&2 (Fig. 3) nucleotide sequences.

Species complexes in the genus Orthetrum have been uncovered by DNA sequence analyses. Based on molecular phylogeny and morphological characteristics, Orthetrum internum McLachlan, 1894 (previously regarded as O. japonicum internum McLachlan, 1894) is resolved as a genuine/distinct species from O. japonicum japonicum (Uhler, 1858) 2,12. Likewise, O. triangulare and the allied taxon $O$. melania are well separated by the nuclear (ITS1 and ITS2) and mitochondrial (COI and 16S rRNA) genes ${ }^{3}$. Additionally, O. melania is separated into four subgroups: O. m. melania (mainland Japan), $O$. $m$. continentale (China, Korea and Taiwan), O. m. yaeyamense (Yaeyama Island, Japan), and O. m. ryukyuense (Amami, Kerama, Okinawa and Tokara, Japan).

In the present study, the nuclear $28 \mathrm{~S}$ rDNA nucleotide sequences were highly conserved and could not resolve congeneric species of Orthetrum (supplementary Fig. 1). The 28S rRNA gene has been found to be better for resolving deep branching in the Odonata ${ }^{13}$. However, the mitochondrial genes (COI, COII and 16S) and the nuclear ITS1\&2 genes unequivocally separated morphologically similar species, such as the reddish-coloured O. chrysis and O. testaceum and the bluish-coloued species O. glaucum and O. luzonicum (Figs. 1-4, Supplementary Fig. 2). Additionally, the 16S rDNA sequences revealed distinct genetic lineages of (1) O. luzonicum from Peninsular Malaysia and China-Japan, and (2) O. sabina of Peninsular Malaysia and India-Japan-Fiji (Fig. 1).

In the phylogeny based on nine Japanese Orthetrum species, $O$. pruinosum neglectum clusters with $O$. melania ${ }^{2}$. The present study based on the ITS1\&2 (Fig. 3), COI (Fig. 2), 16S rDNA (Fig. 1) and combined COI + 16S rDNA (Fig. 5) nucleotide sequences and with more extensive taxon sampling indicates that $O$. pruinosum neglectum clusters nearer to O. testaceum than O. melania. The allied/sibling taxon O. pruinosum schneideri is grouped with $O$. chrysis (Figs. 1-5, Supplementary Figs. 2-4). It is distinctly separated from O. pruinosum neglectum. The two taxa are, without reasonable doubt, cryptic species of a species complex. In the African dragonfly genus Trithemis, COI and ND1 genes reveal three distinct genetic clusters of $T$. stricta but these taxa could not be identified by using classical taxonomic characters ${ }^{14}$.

In summary, phylogenetic analyses of a more extensive taxon sampling based on nucleotide sequences of mitochondrial and nuclear genes indicate that the various subfamilies of the family Libellulidae and the genus Orthetrum are not resolved unequivocally as monophyletic. The nuclear $28 \mathrm{~S}$ rRNA gene is highly conserved and could not resolve congeneric species of Orthetrum. Individual mitochondrial genes (COI, COII, and 16S rRNA) and combination 


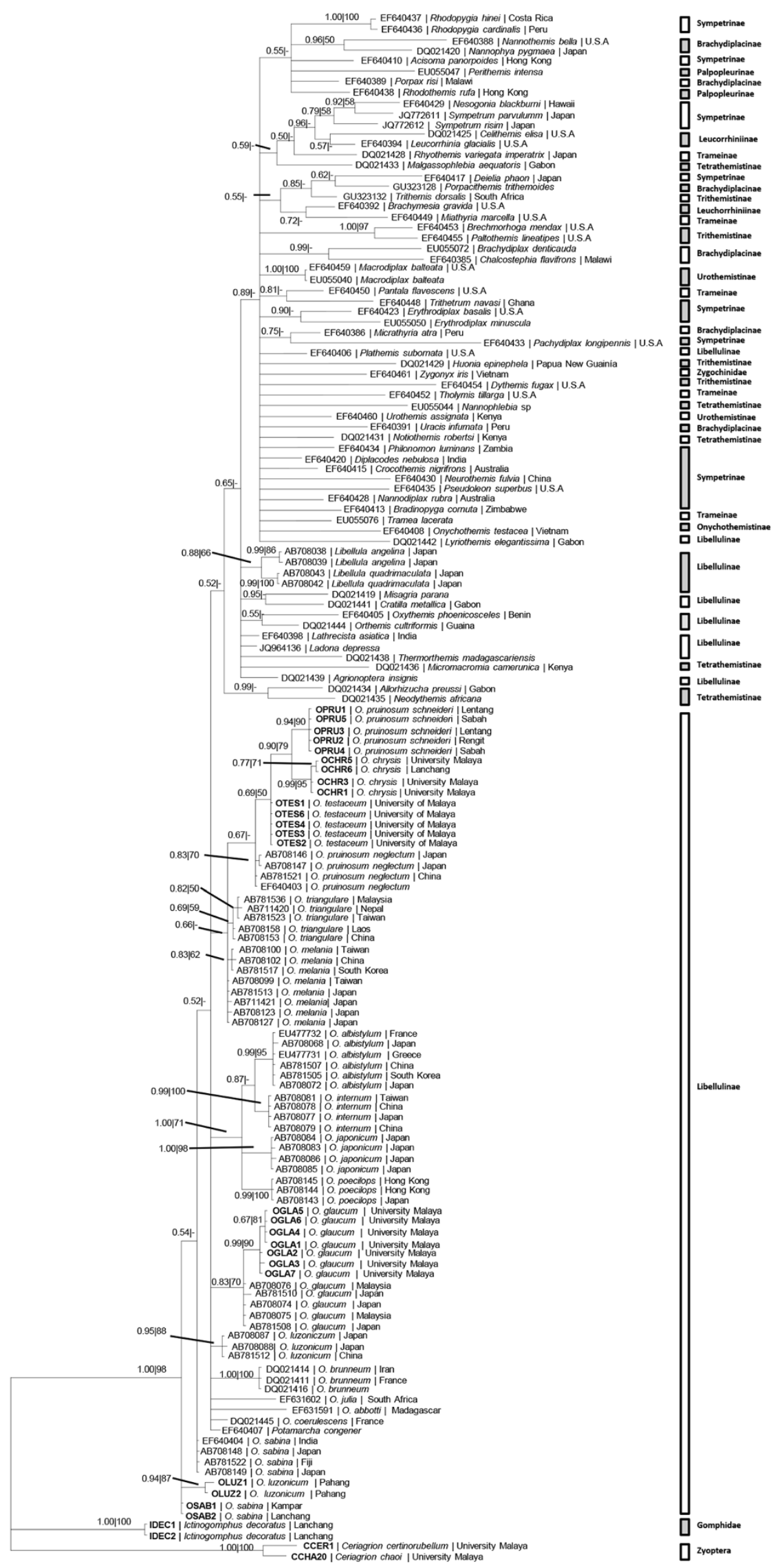

Figure $1 \mid$ BI tree based on $16 \mathrm{~S}$ rDNA nucleotide sequences. Numeric values at the nodes are Bayesian posterior probabilities/ML bootstrap. 


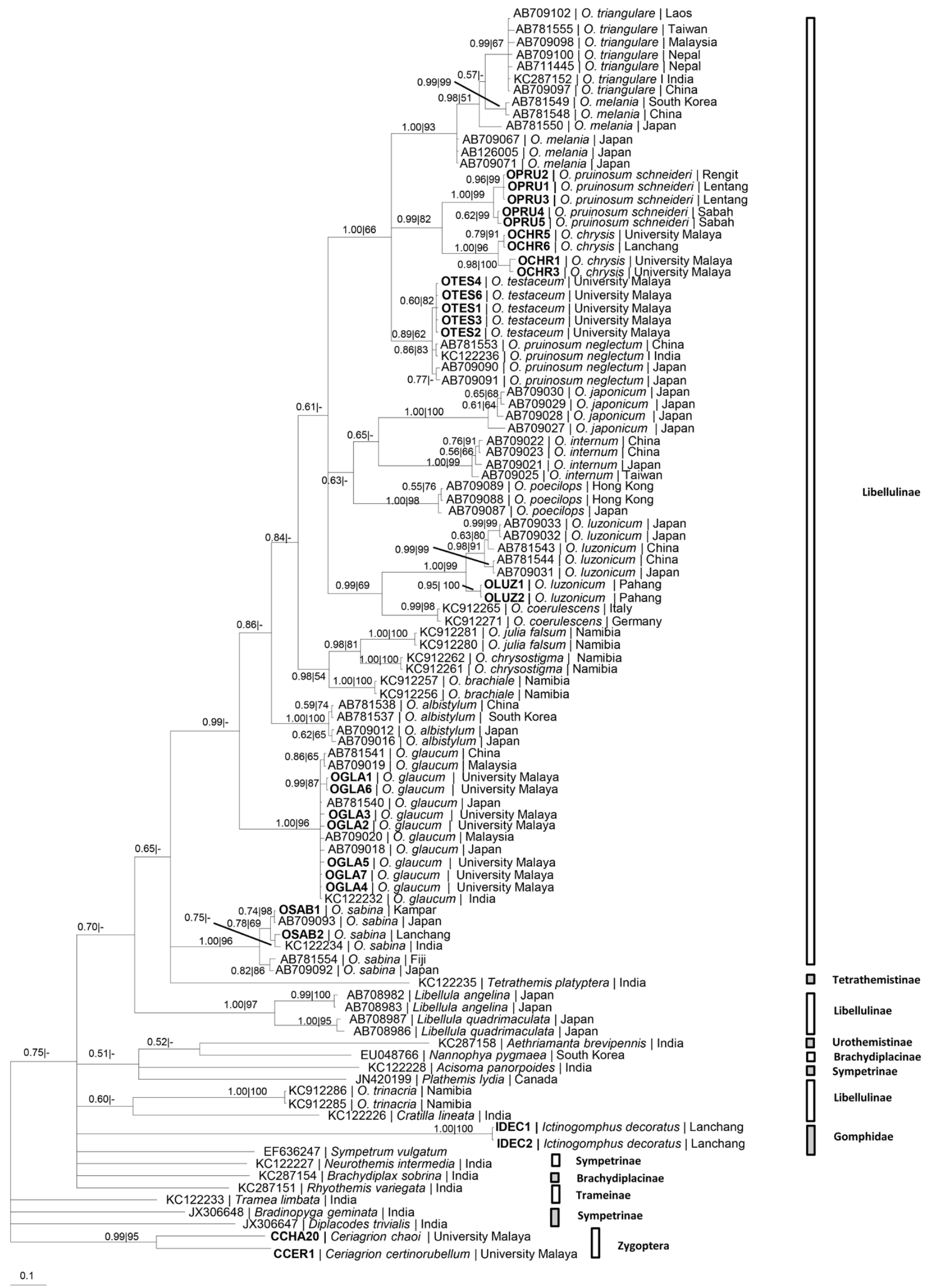

Figure $2 \mid$ BI tree based on COI nucleotide sequences. Numeric values at the nodes are Bayesian posterior probabilities/ML bootstrap. 


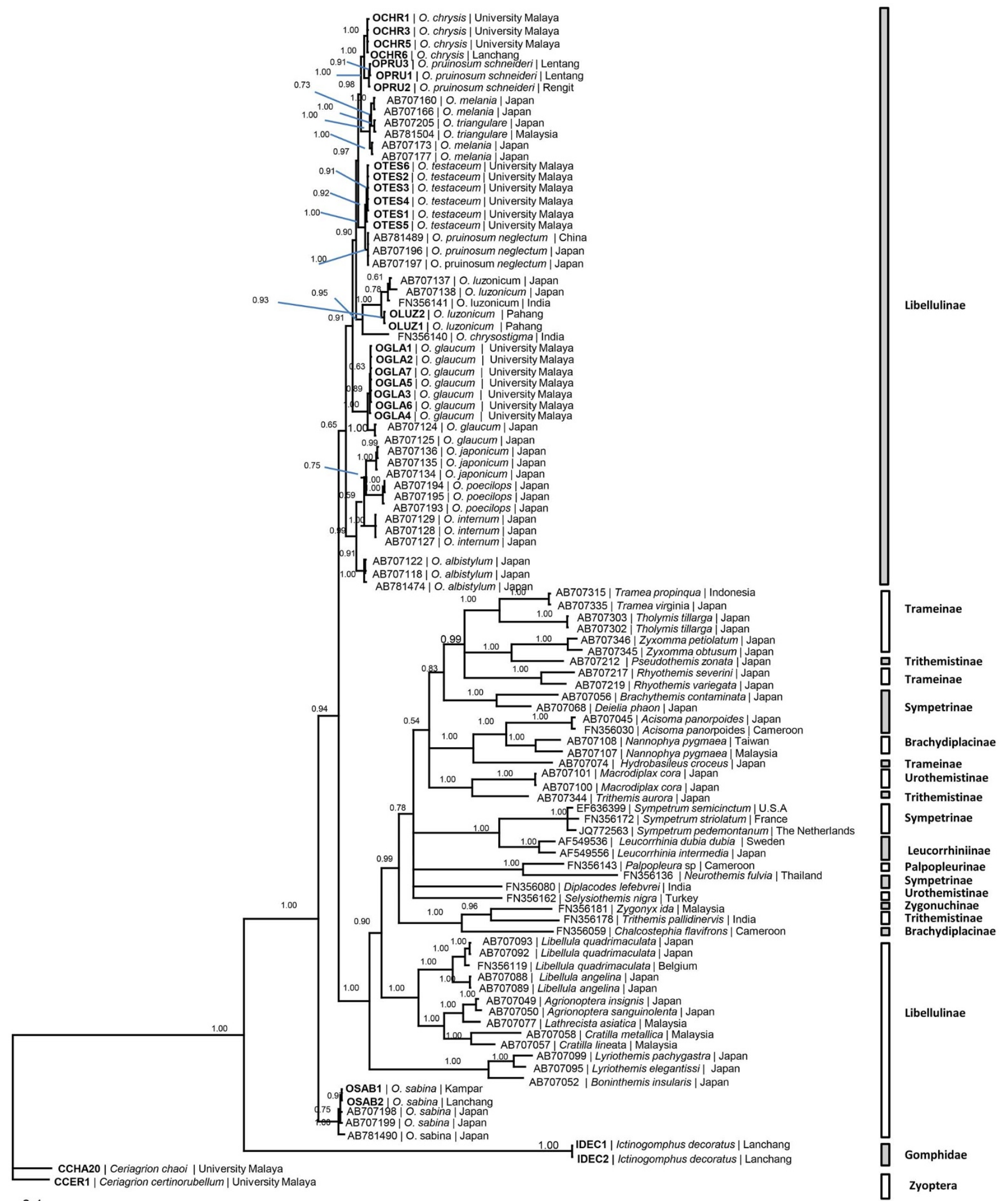
0.1

Figure $3 \mid$ BI tree based on ITS1\&2 nucleotide sequences. Numeric values at the nodes are Bayesian posterior probabilities/ML bootstrap.

of these genes as well as the nuclear ITS1\&2 genes clearly differentiate morphologically similar species, such as the reddish species pairs $O$. chrysis and $O$. testaceum, and the bluish-coloured species O. glaucum and O. luzonicum. This study also reveals distinct genetic lineages between $O$. pruinosum schneideri (occurring in Malaysia) and $O$. pruinosum neglectum (occurring north of Peninsular Malaysia from India to Japan), indicating these taxa are cryptic species. The finding of $O$. pruinosum occurring as a species complex paves the way for an 


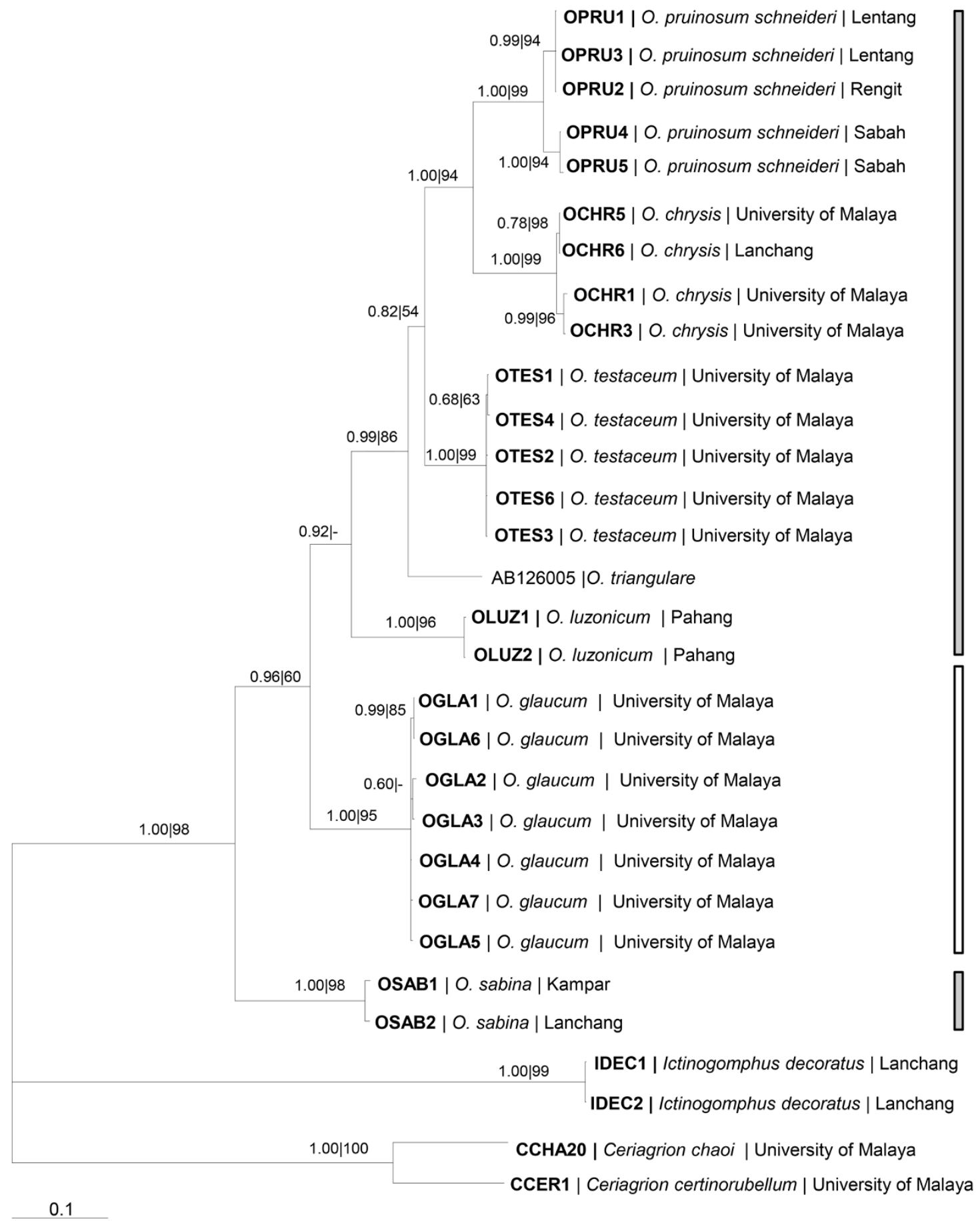

Figure $4 \mid$ BI tree based on COI + COII nucleotide sequences. Numeric values at the nodes are Bayesian posterior probabilities/ML bootstrap.

in-depth phylogeographical study to determine the systematic status of the component taxa. Likewise, phylogeographical studies are needed for O. luzonicum and O. sabina.

\section{Methods}

Ethics statement. No specific permits were required for the described field studies. The dragonflies were collected in disturbed habitats such as open ditches and ponds. No specific permissions were required and the dragonflies are not endangered or protected species.

Specimens. Specimens of the Orthetrum dragonflies for the present study were collected using sweep net or plastic bag. They were identified with established literature ${ }^{15,16}$. In addition, Ictinogomphus decoratus (Anisoptera, Gomphidae) was included for comparison. Two species of Ceriagrion (Zygoptera, Coenagrionidae) were used as outgroup. Details of the species studied are listed in Table 1.
DNA extraction, PCR amplifications and DNA sequencing. The genomic DNA was extracted and PCR amplification was performed as described in Lim et al. ${ }^{17}$ except with variations in annealing temperature for different primers. The primers and annealing temperature for PCR were: COI -F: 5' - ATAATTGGRGGRTTYGGRAAY TG-3' and R: $5^{\prime}$ - CCAAARAATCAAAATAARTGT TG- $3^{\prime \prime 18}$, at $50^{\circ} \mathrm{C}$; COII: C2-J-3102: 5' -AAATGGCAACATGAGCACAAYT-3' and TK-N-3773: 5' -GAGACCAGTACTTGCTTTCAGTCATC- $3^{\prime 19}$ at $50^{\circ} \mathrm{C}$; $16 \mathrm{~S}$ rDNA: $5^{\prime}$-TTGACTGTACAAAGGTAGC- $3^{\prime}$ and $5^{\prime}$-GATATTACGCTGTTATCCC- $3^{\prime 20}$ at $50^{\circ} \mathrm{C}$; $28 \mathrm{~S}$ rDNA: 28sf, 5' ${ }^{\prime}$-AAGGTAGCCAAATGCCTCATC-3' and 28sr, $5^{\prime}$-AGTAGGGTAAAACTAACCT- $3^{\prime}$ at $52^{\circ} \mathrm{C}^{13}$; ITS1: CAS18sF, $5^{\prime}$ - TACACACCGCCCGTCGCTACTA$3^{\prime}$ and CAS5p8sB1d, $5^{\prime}$ - ATGTGCGTTCRAAATGTCGATGTTCA- $3^{\prime 21}$ at $67^{\circ} \mathrm{C}$; and ITS2: CAS5p8sFc, 5' $5^{\prime}$ TGAACATCGACATTTYGAACGCACAT- $3^{\prime}$ and CAS28sB1d, 5'-TTCTTTTCCTCCSCTTAYTRATATGCTTAA- $3^{\prime 21}$ at $55^{\circ} \mathrm{C}$.

The PCR products were assayed by electrophoresis on $1.0 \%$ agarose mini gels stained with SYBR ${ }^{\circledR}$ Safe DNA gel stain (Invitrogen, USA) and visualised under UV light. The amplicons were isolated and purified using the LaboPassTM PCR puri- 

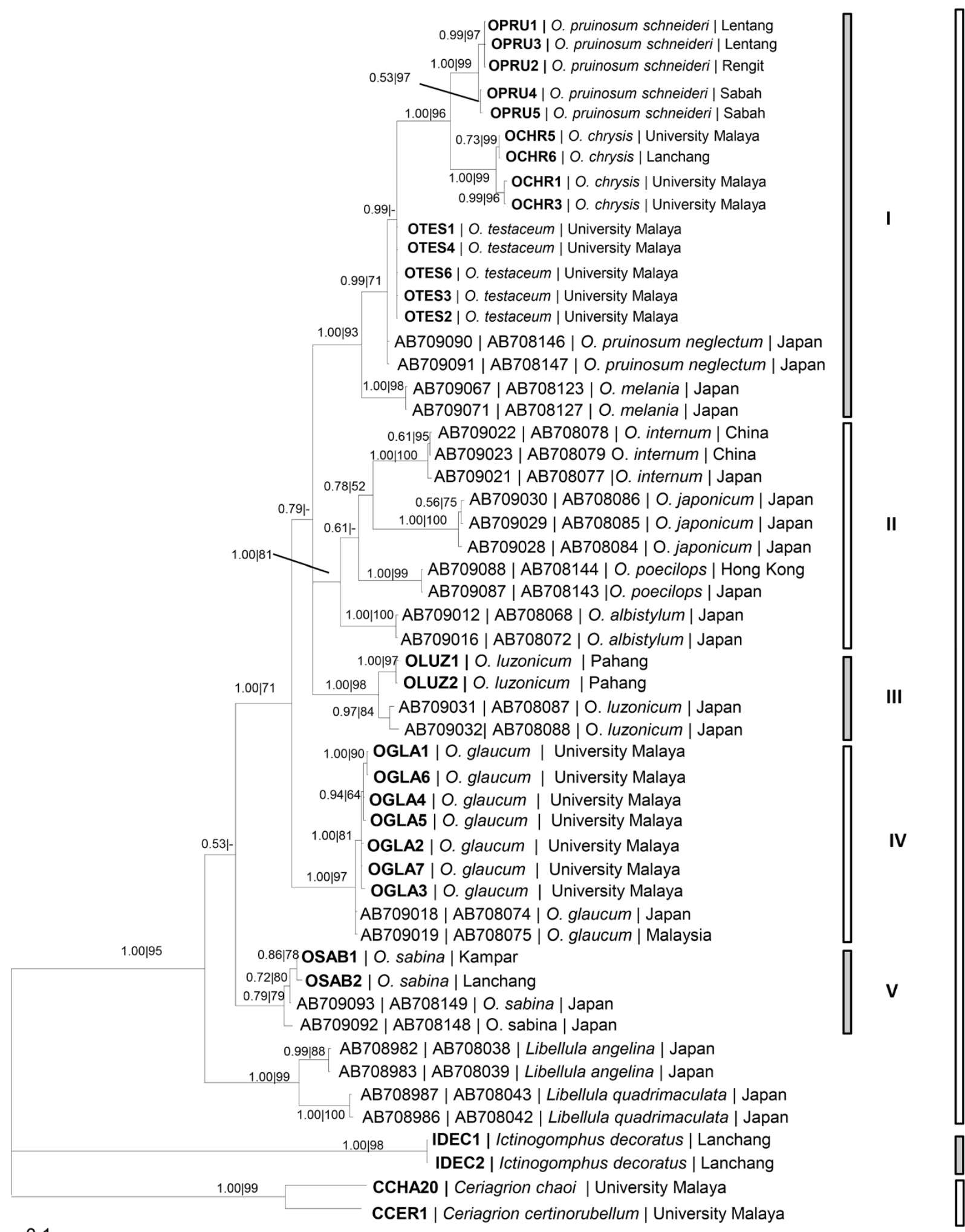

Libellulinae

Gomphidae

Zygoptera 0.1

Figure $5 \mid$ BI tree based on COI $+16 \mathrm{~S}$ rDNA nucleotide sequences. Numeric values at the nodes are Bayesian posterior probabilities/ML bootstrap.

fication kit (Cosmo Genetech, South Korea). The purified PCR products were sent to a commercial company for sequencing. The same set of PCR primers were used for DNA sequencing. Samples were sequenced using BigDyeH Terminator v3.1 Sequencing Kit and analysed on an ABI PRISMH 377 Genetic Analyser.

Genetic divergence. To assess the parsimony information of the sequences of the data sets and species level variation of Orthetrum species, selected specimens were used to measure the uncorrected $(\mathrm{p})$ pairwise genetic distances using PAUP* 4.0b10 software ${ }^{22}$. All individual markers and combined mitochondrial markers (COI + 16S rDNA; COI + COII + 16S rDNA; and COI + COII + 16S rDNA + 28S rDNA) were used to estimate uncorrected ( $\mathrm{p}$ ) pairwise genetic distances.

Phylogenetic analysis. To elucidate the phylogenetic relationship among the different species of Orthetrum species, sequences generated from this study were 
Table 1 | Nucleotide sequences of COI, COII, 16S rRNA, 28S rRNA, ITS1 and/or ITS2 sequences for the taxa of Orthetrum of the family Libellulidae used in the present study. Ictinogomphus decoratus (family Gomphidae), Ceriagrion chaoi and C. cerinorubellum (suborder Zygoptera) were used as outgroups. NA, not available

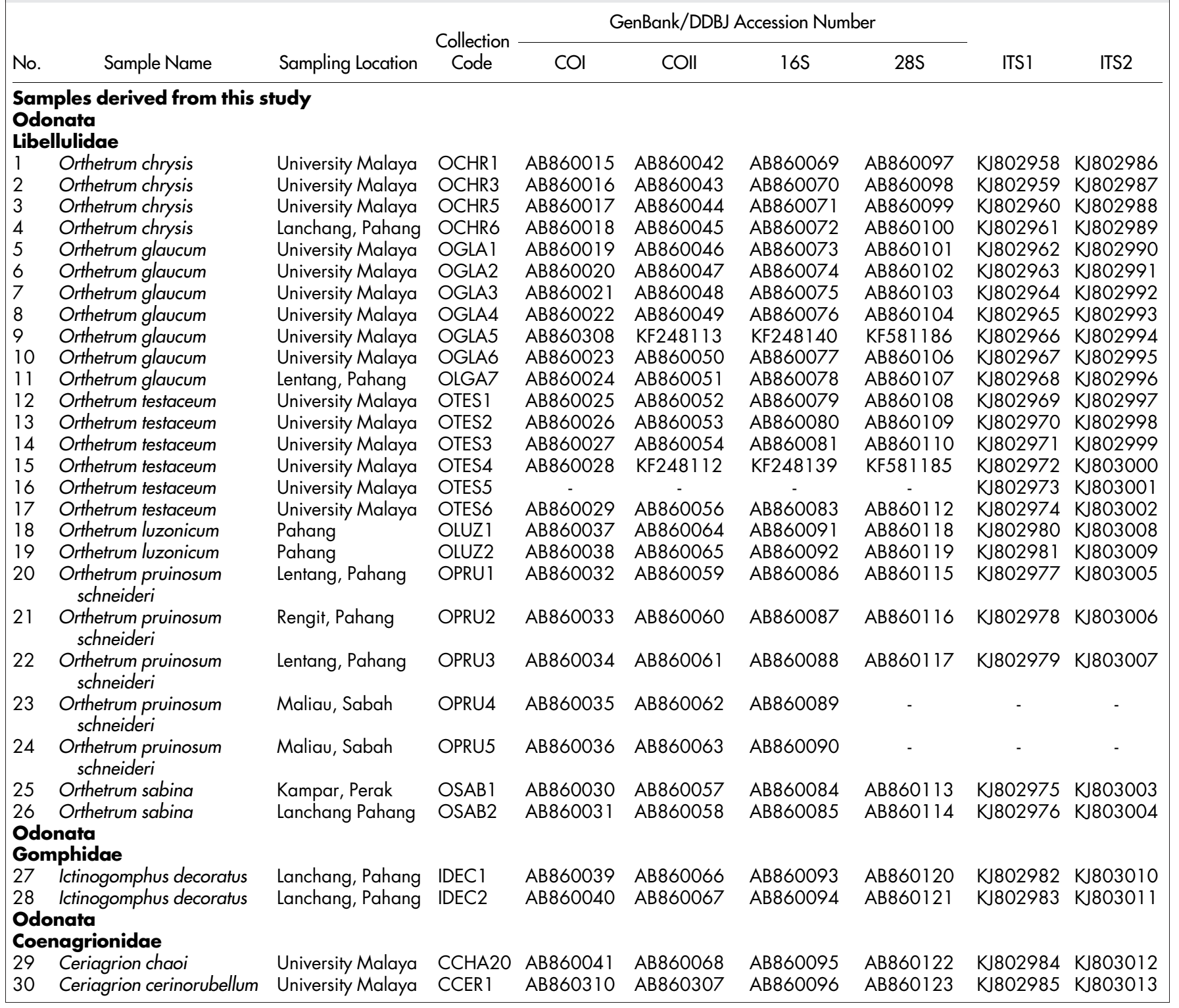

combined with GenBank sequences (Table 1 and Supplementary Table 7) to construct phylogenetic trees. The generated forward and reverse sequences were manually edited and assembled using ChromasPro v1.5 (Technelysium Pty Ltd., Australia) software. The datasets for all genetic markers were aligned using ClustalX ${ }^{23}$. In the preliminary alignment for ITS1 and ITS2, the flanking sequences of $18 \mathrm{~S} \mathrm{rDNA}$ and $5.8 \mathrm{~S} \mathrm{rDNA}$ were included as the guide and were only being trimmed off after final alignment before subjected for phylogenetic analysis. For $28 \mathrm{~S}$ and $16 \mathrm{~S}$, the sequences were aligned using MAFFT $6^{24}$, with Q-INS-i strategy in order to take into account the secondary structure of the RNA. The generated aligned sequences were subjected for the search of the best model to be used for maximum likelihood $(\mathrm{ML})$ and Bayesian Inference (BI) analyses using Kakusan v. $3^{25}$. Best fit models were evaluated using the corrected Akaike Information Criterion for ML and the Bayesian Information Criterion (BIC) for BI with nonpartitioned on the whole sequence. The selected models for ML and BI of each data set are summarised in Supplementary Table 1. ML analysis was performed via Treefinder version October $^{26}$ and BI analysis was performed using MrBayes 3.1.2 $2^{27}$. Bayesian analyses were initiated with a random starting tree and two parallel runs, each of which consisted of running four chains of Markov chain Monte Carlo (MCMC) iterations for $6 \times 10^{6}$ generations. The trees in each chain were sampled every 200th generation. Likelihood values for all postanalysis trees and parameters were evaluated for convergence and burn-in using the "sump" command in MrBayes and the computer program Tracer ver. 1.5 (http://tree. bio.ed.ac.uk/software/tracer/). The first 30,000 trees were discarded as burn-in (where the likelihood values were stabilized prior before the burn in), and the remaining trees after burn-in were used to calculate posterior probabilities using the "sumt" command.

1. Silsby, J. Dragonflies of the world (CSIRO Publishing, Collingwood, 2001).

2. Karube, H., Futahashi, R., Sasamoto, A. \& Kawashima, I. Taxonomic revision of Japanese odonate species, based on nuclear and mitochondrial gene genealogies and morphological comparison with allied species. Part I. Tombo, Fukui 54, 75-106 (2012).

3. Sasamoto, A. \& Futahashi, R. Taxonomic revision of the status of Orthetrum triangulare and melania group (Anisoptera: Libellulidae) based on molecular phylogenetic analyses and morphological comparisons, with a description of three new subspecies of melania. Tombo, Fukui 55, 57-82 (2013).

4. Artiss, T., Schultz, T. R., Polhemus, D. A. \& Simon, C. Molecular phylogenetic analysis of the dragonfly genera Libellula, Ladona, and Plathemis (Odonata: Libellulidae) based on mitochondrial cytochrome oxidase I and 16S rRNA sequence data. Mol. Phylogenet. Evol. 18, 348-361 (2001).

5. Ware, J., May, M. \& Kjer, K. Phylogeny of the higher Libelluloidea (Anisoptera: Odonata): an exploration of the most speciose superfamily of dragonflies. Mol. Phylogenet. Evol. 45, 289-310 (2007). 
6. Fleck, G., Brenk, M. \& Misof, B. Larval and molecular characters help to solve phylogenetic puzzles in the highly diverse dragonfly family Libellulidae (Insecta: Odonata: Anisoptera): The Tetrathemistinae are a polyphyletic group. Org. Divers. Evol. 8, 1-16 (2008).

7. Fleck, G. et al. A phylogeny of anisopterous dragonflies (Insecta, Odonata) using mtRNA genes and mixed nucleotide/doublet models. J. Zool. Syst. Evol. Res. (2008) 46, 310-322 (2008).

8. Dijkstra, K.-D. B. \& Vick, G. S. Inflation by venation and the bankruptcy of traditional genera: the case of Neodythemis and Micromacromia, with keys to the continental African species and the description of two new Neodythemis species from the Albertine Rift (Odonata: Libellulidae). Int. J. Odonatol. 9, 51-70 (2006).

9. Pilgrim, E. M. \& von Dohlen, C. D. Phylogeny of the Sympetrinae (Odonata: Libellulidae): further evidence of the homoplasious nature of wing venation. Syst. Ent. 33, 159-174 (2008).

10. Blanke, A., Greve, C., Mokso, R., Beckman, F. \& Misof, B. An updated phylogeny of Anisoptera including formal convergence analysis of morphological characters. Syst. Ent. 38, 474-490 (2013).

11. Bybee, S. M., Ogdenb, T. H., Branhama, M. A. \& Whiting, M. F. Molecules, morphology and fossils: a comprehensive approach to odonate phylogeny and the evolution of the odonate wing. Cladistics 24, 477-514 (2008).

12. Futahashi, R. A revisional study of Japanese dragonflies based on DNA analyses. Tombo, Fukui 53, 67-74 (2011). (in Japanese).

13. Hasegawa, E. \& Kasuya, E. Phylogenetic analysis of the insect order Odonata using $28 \mathrm{~S}$ and $16 \mathrm{~S}$ rDNA sequences: a comparison between data sets with different evolutionary rates. Entomol. Sci. 9, 55-66 (2006).

14. Damm, S., Schierwater, B. \& Hadrys, H. An integrative approach to species discovery in odonates: from character-based DNA barcoding to ecology. Mol. Ecol. 19, 3881-3893 (2010).

15. Orr, A. G. Dragonflies of Peninsular Malaysia and Singapore (Natural History Publications (Borneo), Kota Kinabalu, 2005).

16. Tang, H. B., Wang, L. K. \& Hämäläinen, M. A photographic guide to the dragonflies of Singapore (The Raffles Museum of Biodiversity Research, Singapore, 2010).

17. Lim, P. E., Tan, J., Suana, I. W., Eamsobhana, P. \& Yong, H. S. Distinct genetic lineages of Bactrocera caudata (Insecta: Tephritidae) revealed by $\mathrm{COI}$ and $16 \mathrm{~S}$ DNA sequences. PLoS ONE 7, e37276 (2012).

18. Hayashi, F., Dobata, S. \& Futahashi, R. Disturbed population genetics: suspected introgressive hybridization between two Mnais damselfly species (Odonata). Zool. Sci. 22, 869-881 (2005)

19. Jordan, S., Simon, C. \& Polhemus, D. Molecular systematics and adaptive radiation of Hawaii's endemic damselfly genus Megalagrion (Odonata:Coenagrionidae). Syst. Biol. 52, 89-109 (2003).

20. Schmitz, J. \& Moritz, R. F. A. Molecular phylogeny of Vespidae (Hymenoptera) and the evolution of sociality in wasps. Mol. Phylogenet. Evol. 9, 183-191 (1998).

21. Ji, Y.-J., Zhang, D.-X. \& He, L.-J. Evolutionary conservation and versatility of a new set of primers for amplifying the ribosomal internal transcribed spacer regions in insects and other invertebrates. Mol. Ecol. Notes 3, 581-585 (2003).

22. Swofford, D. L. PAUP: Phylogenetic analysis using parsimony (and other methods) (Sinauer Associates, Sunderland, Massachusetts, 2002).
23. Thompson, J. D., Gibson, T. J., Plewniak, F., Jeanmougin, F. \& Higgins, D. G. The ClustalX windows interface: flexible strategies for multiple sequence alignment aided by quality analysis tools. Nucl. Acids Res. 24, 4876-4882 (1997).

24. Katoh, K., Asimenos, G. \& Toh, H. Multiple alignment of DNA sequences with MAFFT. Bioinformatics for DNA Sequence Analysis. Posada, D. (ed.) 39-54 (Humana Press, New York, 2009).

25. Tanabe, A. S. Kakusan: a computer program to automate the selection of a nucleotide substitution model and the configuration of a mixed model on multilocus data. Mol. Ecol. Notes 7, 962-964 (2007).

26. Jobb, G., von Haeseler, A. \& Strimmer, K. Treefinder: a powerful graphical analysis environment for molecular phylogenetics. BMC Evol. Biol. 4, 18 (2004)

27. Huelsenbeck, J. P. \& Ronquist, F. MrBayes: Bayesian Inference of phylogenetic trees. Bioinformatics 17, 754-755 (2001)

\section{Acknowledgments}

This study was funded in part by MoHE-HIR Grant (H-50001-00-A000025) and the University of Malaya (H-5620009). We thank our institutions for providing various research facilities and other support

\section{Author contributions}

H.S.Y. and P.E.L. conceived the research in collaboration with J.T., Y.F.N., P.E. and I.W.S. H.S.Y., Y.F.N. and I.W.S. collected the specimens. H.S.Y. identified the specimens. J.T. conducted the PCR and P.E.L., J.T. and P.E. performed the phylogenetic analyses. H.S.Y. and P.E.L. wrote the paper in collaboration with the co-authors. H.S.Y. and P.E.L. were responsible for the final manuscript version.

\section{Additional information}

Supplementary information accompanies this paper at http://www.nature.com/ scientificreports

Competing financial interests: The authors declare no competing financial interests.

How to cite this article: Yong, H.S. et al. Molecular phylogeny of Orthetrum dragonflies reveals cryptic species of Orthetrum pruinosum. Sci. Rep. 4, 5553; DOI:10.1038/srep05553 (2014)

This work is licensed under a Creative Commons Attribution-NonCommercialNoDerivs 4.0 International License. The images or other third party material in this article are included in the article's Creative Commons license, unless indicated otherwise in the credit line; if the material is not included under the Creative Commons license, users will need to obtain permission from the license holder in order to reproduce the material. To view a copy of this license, visit http:// creativecommons.org/licenses/by-nc-nd/4.0/ 